\title{
Hiatal hernia after robotic-assisted coronary artery bypass graft surgery
}

\author{
Rami M. Abazid ${ }^{1 \wedge}$, Alireza Khatami ${ }^{1}$, Jonathan G. Romsa ${ }^{1}$, James C. Warrington ${ }^{1}$, Cigdem Akincioglu ${ }^{1}$, \\ Robert Z. Stodilka ${ }^{1}$, Stephanie Fox ${ }^{2}$, Bob Kiaii ${ }^{2,3}$, William C. Vezina ${ }^{1}$ \\ ${ }^{1}$ Division of Nuclear Medicine, London Health Sciences Centre, Victoria Hospital, London, Canada; ${ }^{2}$ Division of Cardiac Surgery, London Health \\ Sciences Centre, London, Canada; ${ }^{3}$ Division of Cardiac Surgery, University of California, Davis Medical Center, Sacramento, CA, USA \\ Contributions: (I) Conception and design: RM Abazid; (II) Administrative support: All authors; (III) Provision of study materials or patients: All \\ authors; (IV) Collection and assembly of data: All authors; (V) Data analysis and interpretation: All authors; (VI) Manuscript writing: All authors; (VII) \\ Final approval of manuscript: All authors. \\ Correspondence to: Rami M. Abazid, MD. Division of Nuclear Medicine, Section of Cardiac Hybrid Imaging, Victoria Hospital, London Health \\ Sciences Centre, 800 Commissioners Road East, PO Box 5010, London, Ontario N6A 5W9, Canada. Email: ramiabazid@yahoo.com.
}

Background: The aim of the present study is to determine the incidence/progression of hiatal hernia $(\mathrm{HH})$ after robotic-assisted coronary artery bypass grafting (RA-CABG) surgery.

Methods: We reviewed the pre- and post-operative computed tomography (CT) of 491 patients who underwent RA-CABG between 2000 and 2017. Post-operative CT was acquired prospectively in a research protocol. CT was reviewed to assess the presence and the size of $\mathrm{HH}$.

Results: We found 444/491 (90.4\%) had pre-operative CT, while 201/491 (40.9\%) had post-operative CT. In total, 155/491 (31.6\%) had both pre- and long-term post-operative CT with a mean follow-up of $6.2( \pm 3.5)$ years. $\mathrm{HH}$ was more prevalent on post-operative CT, 64/155 (41.3\%) compared to pre-operative CT, 44/155 (28.4\%), $\mathrm{P}<0.0001$. The diameter of pre-existing $\mathrm{HH} 2.8( \pm 1.8) \mathrm{cm}$ was significantly greater after surgery $3.9( \pm 2.5) \mathrm{cm}, \mathrm{P}<0.0001$. As well the volume of the pre-existing HH $5.8(4.4-9.2) \mathrm{mL}$ (quartile) was significantly greater after surgery $14.1(7.2-64.9) \mathrm{mL}, \mathrm{P}<0.0001 .20 / 155$ (12.9\%) had a newly developed $\mathrm{HH}$ after RA-CABG. A binary multivariate regression including $\mathrm{HH}$ risk factors showed that male gender is a predictor of developing a HH after RA-CABG with Hazard Ratio of 3.038, confidence interval (1.10-8.43), $\mathrm{P}=0.033$.

Conclusions: RA-CABG is associated with an increased risk of developing $\mathrm{HH}$ and increases the size of pre-existing $\mathrm{HH}$.

Keywords: Hiatal hernia (HH); coronary artery bypass grafting (CABG); robotic-assisted

Submitted Aug 02, 2020. Accepted for publication Nov 20, 2020.

doi: $10.21037 /$ jtd-20-2557

View this article at: http://dx.doi.org/10.21037/jtd-20-2557

\section{Introduction}

Hiatal hernia $(\mathrm{HH})$ is a protrusion of the esophagogastric junction including a portion of stomach or abdominal contents through the esophageal hiatus into the chest cavity (1). The etiology and pathogenesis of non-congenital
HHs is unclear. There are multiple factors that predispose to $\mathrm{HH}$ including advanced age, male gender, chronic obstructive pulmonary diseases (COPDs), smoking and obesity (2). Iatrogenic $\mathrm{HH}$ has been reported as a complication after esophageal hiatus dissection during surgical procedures such as esophagomyotomy, antireflux

^ ORCID: 0000-0002-8504-1930. 


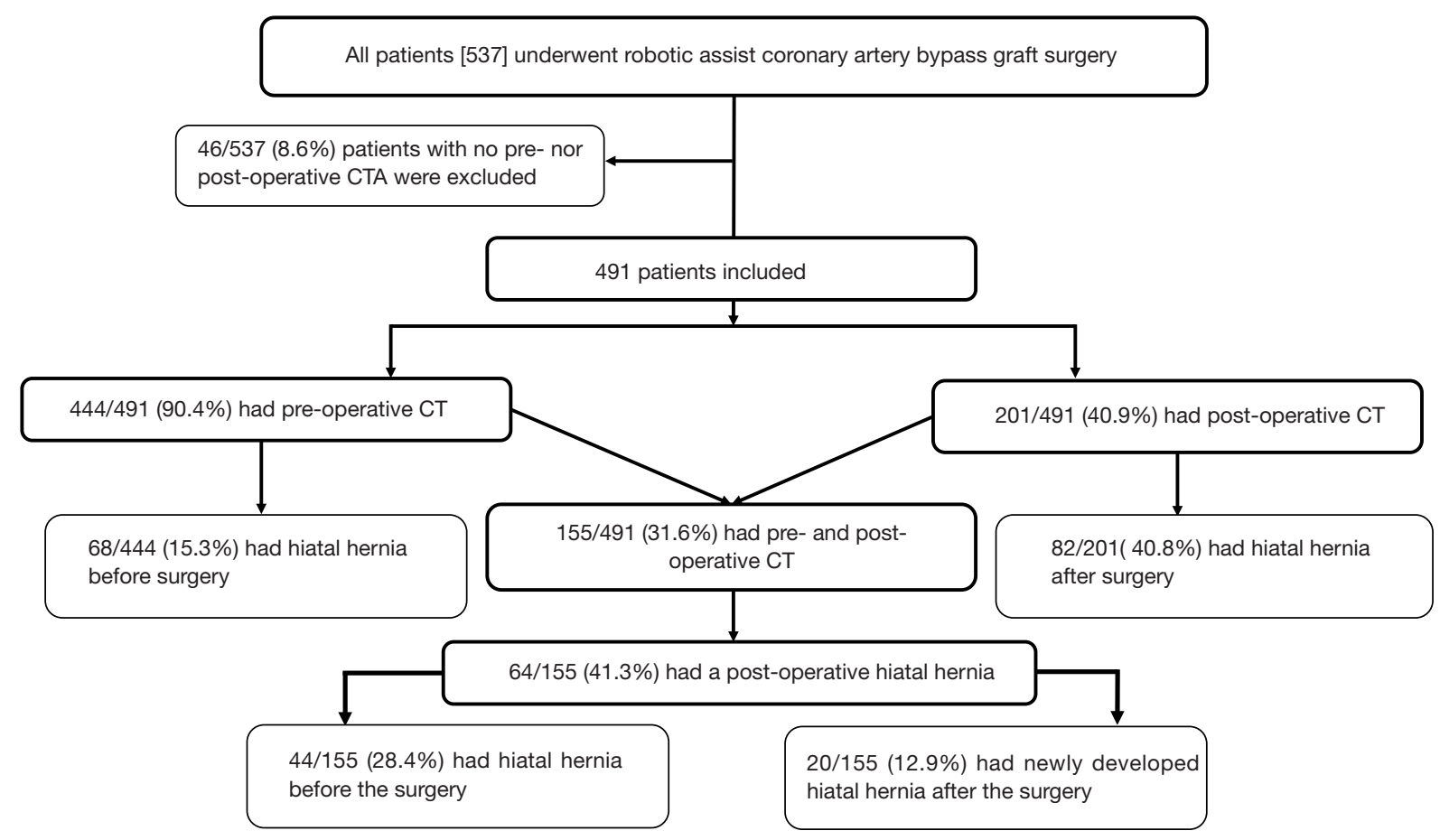

Figure 1 Patient inclusion.

surgery or partial gastrectomy (3). The prevalence of $\mathrm{HH}$ in adults ranges between $10-20 \%(4,5)$. The vast majority are asymptomatic or have vague symptoms e.g., epigastric pain, nausea and postprandial fullness. In acute cases, symptoms are mostly related to bowel ischemia or obstruction $(3,4,6,7)$. The size of a HH may vary from small to large where most of the stomach migrates into the chest cavity $(3,4)$. There are various modalities to diagnose $\mathrm{HH}$ such as esophagogastroduodenoscopy, barium swallow radiography, esophageal manometry, $\mathrm{pH}$ testing and computed tomography (CT). CT can provide information about the type and the size of the hernia $(5,8,9)$.

Minimally invasive robotic-assisted cardiac surgery is a technique used in the treatment of coronary artery disease and valvular heart diseases. It is an alternative approach to conventional sternotomy. Robotic-assisted coronary artery bypass grafting (RA-CABG) has been shown to be comparable to conventional CABG in terms of longterm survival and graft patency with less post-operative complications and shorter post-operative recovery time $(10,11)$. RA-CABG requires a minithoracotomy at the $3^{\text {rd }}$, $4^{\text {th }}$, or $5^{\text {th }}$ left intercostal space followed by removal of the pericardial fat pad and a pericardiotomy to perform the coronary anastomosis on a beating heart. Heart suction stabilizers are routinely applied through one of the endoscopic port incisions to reduce the motion of the target area and perform the operation using off cardiopulmonary bypass pump technique (12). These maneuvers may result in anterior and cephalad re-orientation of the heart position (13) and may affect the cardiac-esophageal-hiatus relationship leading to a stretching of the phrenoesophageal membrane and elevation of the esophageal-gastric junction (EGJ) above the hiatus (3). In this study using CT, we determined the incidence of new $\mathrm{HH}$ and enlargement of pre-existing $\mathrm{HH}$ in patients who underwent RA-CABG between 2000 and 2017. We present the following article in accordance with the STROBE reporting checklist (available at http://dx.doi.org/10.21037/jtd-20-2557).

\section{Methods}

\section{Study population}

We reviewed the CT of patients who underwent RA-CABG between 2000 and 2017. They also agreed to return for a long-term follow-up coronary CT angiogram as part of research protocol. For patients who had more than one post-operative CT, the latest was reviewed. All patients who did not have had a pre- and post-operative CT were 

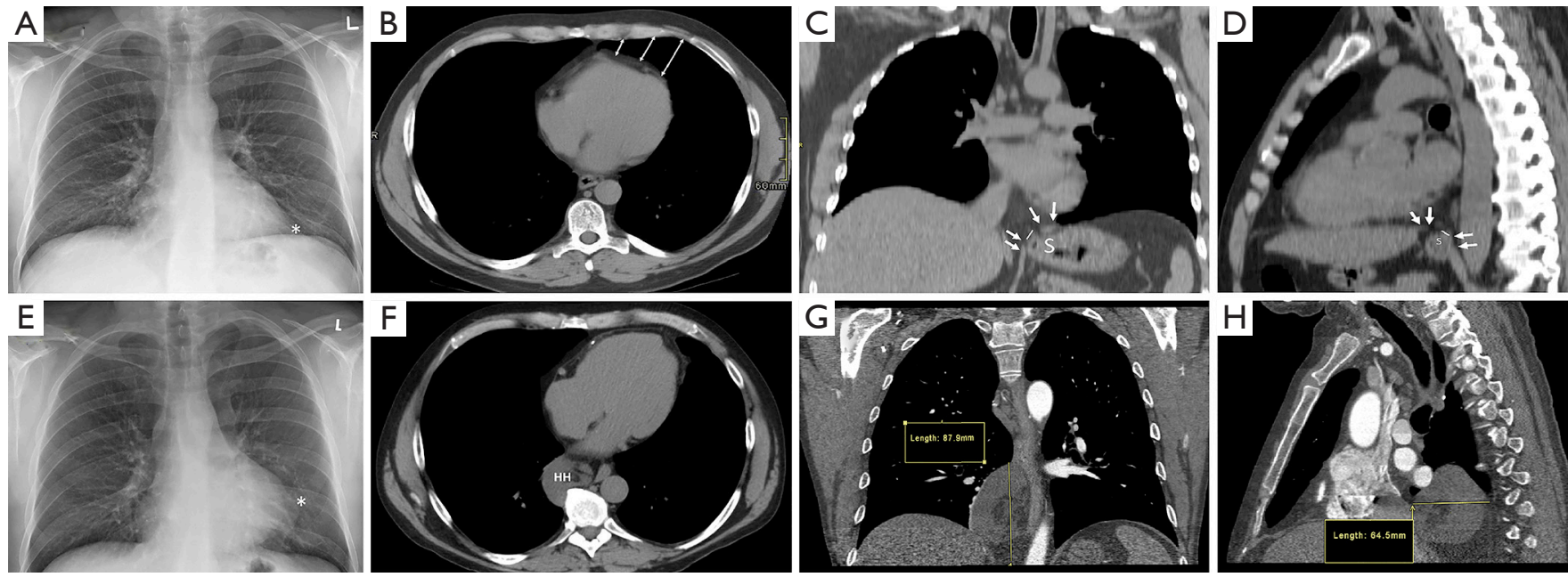

Figure 2 Images before and after RA-CABG. (A) Pre-operative CXR with normal apex position (asterisk). (B) Axial non-enhanced cCTA image illustrates the normal intra-thoracic heart location and the white double-arrows represent the anterior cardiac space prior to RACABG. (C) Pre-operative non-enhanced coronal, and (D) pre-operative non-enhanced sagittal CT image show the stomach (S) and esophageal-gastric junction (white line) below the diaphragm (white arrows). (E) Post-operative CXR shows a boot-shaped heart with upward pointing apex (asterisk). (F) Axial non-enhanced CT image illustrates the heart shifting anterolaterally. (G) Post-operative cCTA coronal image illustrating the hiatal hernia measurement, and $(\mathrm{H})$ post-operative cCTA sagittal image indicating the size of the hiatal hernia. RA-CABG, robotic-assisted coronary artery bypass grafting; cCTA, coronary computed tomography angiography; CXR, chest X-ray.

excluded Figure 1. This study was approved by our local human ethics committee and all patients signed a consent for follow-up studies. This study was approved by our local human ethics committee (The Cardiovascular Registry - 13575E). All patients signed a consent for follow-up studies. The study was conducted in accordance with the Declaration of Helsinki (as revised in 2013). HH risk factors including age, gender, body mass index and history of COPD were recorded for all patients.

\section{CT scan evaluation}

The pre- and post-operative CTs were reviewed by a fully trained diagnostic radiologist. HH was defined as displacement of GEJ by more than $2 \mathrm{~cm}$ above the esophageal hiatus (2). The esophageal hiatus level was delineated with an oblique line in a magnified view in the sagittal plane. The $\mathrm{HH}$ diameter was determined using the average maximum measurements of the $\mathrm{HH}$ in the axial, coronal and sagittal planes (Figure 2). HH volume preand post-operatively was calculated using the formula of a sphere $v=\frac{4}{3} \pi r^{3}$, where $\mathrm{r}$ is the radius of the sphere. $\mathrm{HH}$ was classified into four types: Type I (sliding) where only the gastric cardia slides upward, Type II (paraesophageal) where the anterior gastric wall protrudes into the chest cavity while the GEJ is preserved, Type III (a combination of Type I and Type II) and Type IV (giant paraesophageal) where more than $50 \%$ of the stomach or other abdominal organs protrude into the chest cavity $(3,4)$.

\section{Statistical analysis}

Quantitative variables were expressed as means \pm standard deviations and categorical variables were expressed as frequencies. McNemar chi-square test was used to compare the categorical variables (frequency of new HH postoperatively compared to pre-operatively) and paired $t$-test to compare the continuous variables (post-operative increase in $\mathrm{HH}$ diameter). Increase in pre-existing $\mathrm{HH}$ volume postoperatively was confirmed with Wilcoxon signed-rank test. $\mathrm{HH}$ volume pre- and post-operatively was not normally distributed; non-parametric descriptive statistics and statistical analysis were used. We performed a multivariate binary regression analysis including all $\mathrm{HH}$ risk factors (age, gender, body mass index and previous history of COPD) to identify predictors of $\mathrm{HH}$ progression. A $\mathrm{P}$ value $<0.05$ was considered statistically significant. All statistical analyses were performed using SPSS for Windows (Version 19.0 
Table 1 Baseline characteristics of all patients

\begin{tabular}{|c|c|}
\hline Variables & Value \\
\hline No. of patients & 491 \\
\hline Age (year), mean $\pm S D$ & $61.6 \pm 10$ \\
\hline Male sex, n (\%) & $359(73.0)$ \\
\hline Diabetes mellitus, $\mathrm{n}(\%)$ & $89(18.0)$ \\
\hline Peripheral vascular diseases, n (\%) & $14(2.9)$ \\
\hline Body mass index $\left(\mathrm{kg} / \mathrm{m}^{2}\right)$, mean $\pm \mathrm{SD}$ & $28.9 \pm 6.1$ \\
\hline History of CVA, n (\%) & $45(9.2)$ \\
\hline Atrial fibrillation, $\mathrm{n}(\%)$ & $38(7.7)$ \\
\hline History of COPD, n (\%) & $33(6.6)$ \\
\hline \multicolumn{2}{|c|}{ Dyspnea NYHA Class before RA-CABG, n (\%) } \\
\hline No dyspnea & $208(42.4)$ \\
\hline Class I & $231(47.0)$ \\
\hline Class II & $16(3.3)$ \\
\hline Class III & $35(7.1)$ \\
\hline Class IV & $1(0.2)$ \\
\hline \multicolumn{2}{|l|}{ Angina CCS Class before RA-CABG, $n(\%)$} \\
\hline No angina & $64(13.0)$ \\
\hline Class I & $32(6.5)$ \\
\hline Class II & $37(7.5)$ \\
\hline Class III & $221(45.0)$ \\
\hline Class IV & $101(20.6)$ \\
\hline Creatinine $(\mathrm{mmol} / \mathrm{dL})$, mean $\pm \mathrm{SD}$ & $86 \pm 25$ \\
\hline Elective surgery, n (\%) & $411(83.7)$ \\
\hline \multicolumn{2}{|c|}{$\begin{array}{l}\text { COPD, chronic obstructive pulmonary disease; CVA } \\
\text { cerebrovascular accident; NYHA, New York Heart Association } \\
\text { CCS, Canadian Cardiovascular Society; RA-CABG, robotic- } \\
\text { assisted coronary artery bypass grafting. }\end{array}$} \\
\hline
\end{tabular}

SPSS Inc., Chicago, IL, USA).

\section{Results}

A total of 491 patients were included in the study. The mean age of the patients at the first CT was $61.6( \pm 10)$ years. $359 / 491$ (73\%) were men. Other baseline characteristics are shown in Table 1. Of all patients, 444/491 (90.4\%) had preoperative CT and 201/491 (40.8\%) also had post-operative CT. In the 444 patients with pre-operative CT, HH was found pre-operatively in 68/444 (15.3\%), of which $63 / 444$
Table 2 Multivariate binary regression of hiatal hernia risk factors

\begin{tabular}{lcccc}
\hline \multirow{2}{*}{ Variable } & HR & \multicolumn{2}{c}{$\mathrm{HR}(95 \% \mathrm{Cl})$} & \multirow{2}{*}{ P value } \\
\cline { 3 - 4 } & & Lower & Upper & \\
\hline Age (year) & 1.01 & 1.00 & 1.09 & 0.11 \\
Male gender & 3.04 & 1.10 & 8.43 & 0.03 \\
History of COPD & 0.02 & 0.01 & 0.63 & 0.91 \\
Body mass index & 1.00 & 0.90 & 1.08 & 0.73 \\
\hline
\end{tabular}

Only male gender was statistically significant. HR, hazard ratio; COPD, chronic obstructive pulmonary disease.

(14.2\%) were Type I, 4/444 (0.9\%) were Type II, $1 / 444$ $(0.2 \%)$ were Type III and 0/444 (0\%) were Type IV HH. In the 201 patients with post-operative CT, the prevalence of $\mathrm{HH}$ was $82 / 201(40.8 \%)$ with the following distribution: 60/201 (29.9\%) Type I, 18/201 (8.9\%) Type II, 3/201 (1.5\%) Type III and 1/201 (0.5\%) Type IV HH.

In total, 155/491 (31.6\%) had both pre-and post-operative CT with a follow-up range between $0.5-13.6$ years with a mean of $6.2( \pm 3.5)$ year. In these patients, $\mathrm{HH}$ was more prevalent on the post-operative CT, [64/155 (41.3\%) vs. 44/155 (28.4\%), $\mathrm{P}<0.0001]$. Of these 155 patients, 20/155 (12.9\%) developed a HH after RACABG and 44/155 (28.4\%) had a pre-existed HH before surgery. In those with pre-existing $\mathrm{HH}$ using paired $t$-test, pre-existing $\mathrm{HH}$ diameter was significantly greater after surgery, $2.8( \pm 1.8)$ vs. $3.9( \pm 2.5) \mathrm{cm}, \mathrm{P}<0.0001$. Pre-existing $\mathrm{HH}$ volume was significantly greater after surgery 14.1 (7.2-64.9) vs. 5.8 (4.4-9.2) mL (median with quartiles), $\mathrm{P}<0.0001$. Binary multivariate regression including all known $\mathrm{HH}$ risk factors showed male gender was the sole predictor of developing a HH after RA-CABG with hazard ratio of 3.04, (95\% confidence interval 1.10-8.43), $\mathrm{P}=0.03$. Other risk factors are shown in Table 2.

During follow-up, two patients developed esophageal cancer and one patient had a large $\mathrm{HH}$, the latter underwent a gastric fundoplication Figure 3.

\section{Discussion}

We report a high incidence of newly developed $\mathrm{HH}$ on CT after RA-CABG. In patients with both pre- and post-operative CT, 20/155 (12.9\%) developed new HH. 44/155 (28.4\%) with pre-existing HH prior to surgery had enlargement of the $\mathrm{HH}$ post-operatively. Male gender was a predictor for the development of a new $\mathrm{HH}$ after surgery. 

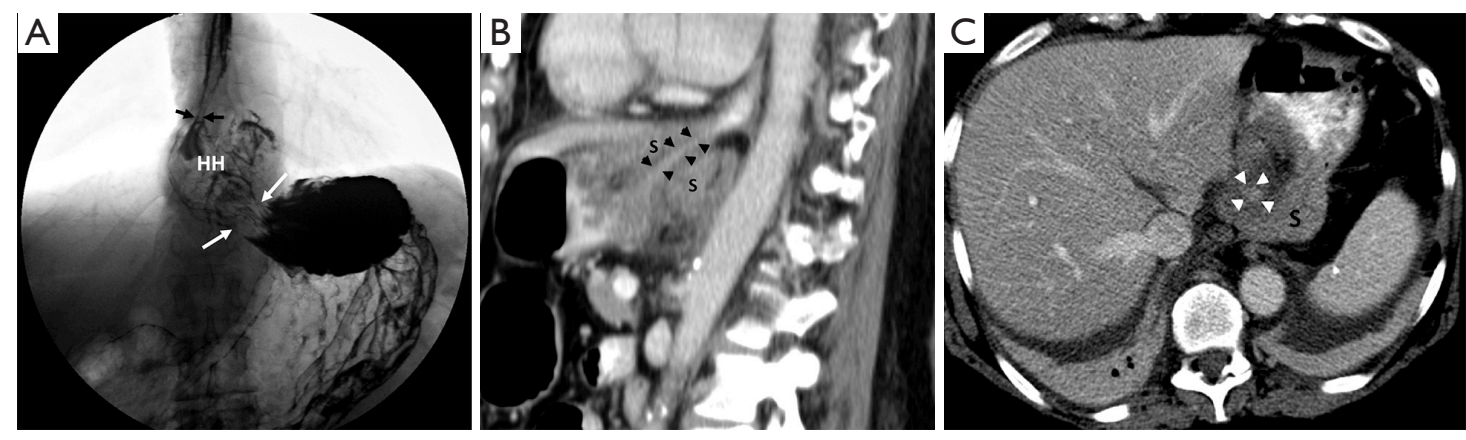

Figure 3 Post-operative HH before and after fundoplication. (A) Barium swallow study before fundoplication surgery. The gastroesophageal junction (black arrows) and the herniated gastric fundus (HH) are seen above the diaphragm (white arrows). (B) Sagittal and (C) axial CT images post-fundoplication surgery demonstrates an infra-diaphragmatic esophagus (arrows head) surrounded by a gastric wrap (S). $\mathrm{HH}$, hiatal hernia.

The esophageal hiatus is an elliptically-shaped orifice and is the most vulnerable diaphragmatic opening to herniation. The right diaphragmatic crus provides substantial support to prevent herniation of the abdominal contents into the mediastinum during pressure variations between the abdominal and chest cavities. Two important components are required to maintain hiatus integrity. First, a sufficient amount of elastic tissue is needed. This tends to decline with age correlating with the increase in $\mathrm{HH}$ prevalence among the elderly. Secondly, preservation of the relationship between the esophagus and adjacent structures such as the surrounding diaphragmatic crura is required (14) which may be affected after regional EGJ surgery (3).

Previous reports have shown that acquired $\mathrm{HHs}$ are more common in smokers and in patients with COPD possibly due to chronically increased intra-abdominal pressure (2). There are three reported cases (15-17) of acute cardiac tamponade resulting from post-surgical giant $\mathrm{HH}$ which developed immediately after conventional CABG, RA-CABG and post aortic dissection repair respectively. The authors attributed these complications to a distended gastric cavity after surgery. Giuricin et al. (18) described a bowel obstruction a few months after CABG due to a $\mathrm{HH}$; the hernia was presumed to be unrecognized prior to surgery. Similarly, iatrogenic HH has been reported as a complication of surgical intervention at the hiatus esophagus (3) due to alteration of the EGJ and the neighboring structures. In comparison to our observation, there is no direct manipulation at the hiatus site during RA-CABG. There are however long-term changes in heart position after RA-CABG which might affect the anatomical relationship between the components supporting the hiatus (13). A short-term effect of the routine induction of iatrogenic pneumothorax with $\mathrm{CO}_{2}$ insufflation into the chest cavity during the surgery (used to increase the intrathoracic pressures up to $10 \mathrm{mmHg}$ ) may result in strain and flattening of the left hemi-diaphragm and possibly weaken the diaphragmatic crus.

The esophagus and the heart have an intimate anatomical relationship with the left atrium and adjacent pericardium located anterior to the esophagus (14). Any change in this relationship due to cardiac reorientation might alter the anatomical orientation of the EGJ supporting tissues making the hiatus more vulnerable to herniation.

Recently, we reported (13) a boot-shaped heart appearance in two-thirds (66\%) of patients post RA-CABG from the upward and lateral shift of the heart. We suggested that cephalad displacement of the heart, accompanied by perioperative increases of intra-thoracic pressure, may lead to the development or progression of $\mathrm{HH}$. To the best of our knowledge, these observations have not been previously reported post RA-CABG. These findings suggest that heart position or location within the chest cavity plays a key role in stabilizing the esophageal sphincter along with possibly the effect of increased intra-thoracic pressure. A change in heart position/location could cause mechanical traction or an alteration in the pressure gradient across the esophageal hiatus increasing the risk for the development of a $\mathrm{HH}$.

Esophageal cancer was diagnosed post-operatively in two of our patients $2 / 201(1 \%)$. This is in contrast to $0.3 \%$ incidence rate of esophageal cancer among Canadians (19). Whether these cases were de novo or consequences of Barrett's esophagus due to chronic gastroesophageal reflux from a $\mathrm{HH}$ is not known. 
Based on the results of the present study, with a moderate to large HH before RA-CABG surgery, patients should undergo discussion about dealing with both $\mathrm{HH}$ and $\mathrm{CABG}$ imultaneously. This may involve either considering miniinvasive surgery to repair the $\mathrm{HH}$ post CABG or switching to open sternotomy approach to prevent the progression of the pre-existing $\mathrm{HH}$ after CABG surgery.

\section{Study limitations}

This is a single center study with CT as the only modality used to assess HH. The long-term CT follow-up was part of outcome study. Gastrointestinal symptoms were not recorded to determine whether acquired $\mathrm{HH}$ affected quality of life. Our study findings cannot be generalized to conventional CABG as only an RA-CABG dataset was analyzed.

\section{Study strengths}

Anatomical finding of $\mathrm{HH}$ imaged using three-dimensional volume imaging with high resolution CT. Pre-existing $\mathrm{HH}$ volume measured pre-operatively and post-operatively in the same patients.

\section{Conclusions}

RA-CABG is associated with the development of $\mathrm{HH}$ by an increase of approximately $12.9 \%$ and significantly increases the size of a pre-existing $\mathrm{HH}$ on long-term CT follow-up.

\section{Acknowledgments}

Funding: This work was supported by the Lawson Research Institute, London, Ontario, Canada.

\section{Footnote}

Reporting Checklist: The authors have completed the STROBE reporting checklist. Available at http://dx.doi. org/10.21037/jtd-20-2557

Data Sharing Statement: Available at http://dx.doi. org/10.21037/jtd-20-2557

Conflicts of Interest: All authors have completed the ICMJE uniform disclosure form (available at http://dx.doi. org/10.21037/jtd-20-2557). RMA, JGR, BK and WCV report other from Lawson Research Institute, London, Ontario, Canada, during the conduct of the study. The other authors have no conflicts of interest to declare.

Ethical Statement: The authors are accountable for all aspects of the work in ensuring that questions related to the accuracy or integrity of any part of the work are appropriately investigated and resolved. This study was approved by our local human ethics committee (the Cardiovascular Registry - 13575E). All patients signed a consent for follow-up studies. The study was conducted in accordance with the Declaration of Helsinki (as revised in 2013).

Open Access Statement: This is an Open Access article distributed in accordance with the Creative Commons Attribution-NonCommercial-NoDerivs 4.0 International License (CC BY-NC-ND 4.0), which permits the noncommercial replication and distribution of the article with the strict proviso that no changes or edits are made and the original work is properly cited (including links to both the formal publication through the relevant DOI and the license). See: https://creativecommons.org/licenses/by-nc-nd/4.0/.

\section{References}

1. Pickhardt PJ, Boyce CJ, Kim DH, et al. Should small sliding hiatal hernias be reported at CT colonography? AJR Am J Roentgenol 2011;196:W400-4.

2. Kim C, Ouyang W, Dass C, et al. Hiatal Hernia on Chest High-Resolution Computed Tomography and Exacerbation Rates in COPD Individuals. Chronic Obstr Pulm Dis 2016;3:570-9.

3. Kahrilas PJ, Kim HC, Pandolfino JE, et al. Approaches to the diagnosis and grading of hiatal hernia. Best Pract Res Clin Gastroenterol 2008;22:601-16.

4. Dean C, Etienne D, Carpentier B, et al. Hiatal hernias. Surg Radiol Anat 2012;34:291-9.

5. Kohn GP, Price RR, DeMeester SR, et al. Guidelines for the management of hiatal hernia. Surg Endosc 2013;27:4409-28.

6. Yu HX, Han CS, Xue JR, et al. Esophageal hiatal hernia: risk, diagnosis and management. Expert Rev Gastroenterol Hepatol 2018;12:319-29.

7. Sihvo EI, Salo JA, Räsänen JV, et al. Fatal complications of adult paraesophageal hernia: a population-based study. J Thorac Cardiovasc Surg 2009;137:419-24.

8. Vas W, Malpani AR, Singer J, et al. Computed 
tomographic evaluation of paraesophageal hernia. Gastrointest Radiol 1989;14:291-4.

9. Eren S, Ciriş F, et al. Diaphragmatic hernia: diagnostic approaches with review of the literature. Eur J Radiol 2005;54:448-59.

10. Ruel M, Une D, Bonatti J, et al. Minimally invasive coronary artery bypass grafting: is it time for the robot? Curr Opin Cardiol 2013;28:639-45.

11. Giambruno V, Chu MW, Fox S, et al. Robotic-assisted coronary artery bypass surgery: an 18-year single-centre experience. Int J Med Robot 2018;14:e1891.

12. Bonatti J, Schachner T, Bonaros N, et al. Robotically assisted totally endoscopic coronary bypass surgery. Circulation 2011;124:236-44.

13. Abazid RM, Akincioglu C, Warrington JC, et al. BootShaped Heart After Robotic Coronary Assist Bypass Surgery. JACC Cardiovasc Imaging 2020;13:2430-4.

14. Heatley M, Rose K, Weston C. The heart and the

Cite this article as: Abazid RM, Khatami A, Romsa JG, Warrington JC, Akincioglu C, Stodilka RZ, Fox S, Kiaii B, Vezina WC. Hiatal hernia after robotic-assisted coronary artery bypass graft surgery. J Thorac Dis 2021;13(2):575-581. doi: $10.21037 /$ jtd-20-2557 oesophagus: intimate relations. Postgrad Med J 2005;81:515-8.

15. Devbhandari MP, Khan MA, Hooper TL, et al. Cardiac compression following cardiac surgery due to unrecognised hiatus hernia. Eur J Cardiothorac Surg 2007;32:813-5.

16. Papoulidis P, Beatty JW, Dandekar U, et al. Hiatal hernia causing extrapericardial tamponade after coronary bypass surgery. Interact Cardiovasc Thorac Surg 2014;19:716-7.

17. Hasegawa Y, Saito T, Horimi H, et al. Hiatal hernia incarceration during cardiopulmonary bypass in a patient with acute aortic dissection-a case report, Nihon Kyobu Geka Gakkai Zasshi 1995;43:1680-3.

18. Giuricin M, Balani A, Giacomel G, et al. Bowel obstruction after cardiac surgery due to diaphragmatic unrecognised hernia. Updates Surg 2012;64:59-61.

19. Canadian Cancer Statistics Advisory Committee (2019). Canadian Cancer Statistics 2019. Toronto, ON: Canadian Cancer Society. 